\title{
Trump Proposes Initial Healthcare Agenda
}

On Friday, November 11, President-elect Trump proposed a healthcare agenda on his website greatagain.gov (1). Yesterday, November 12, he gave an interview on 60 Minutes clarifying his positions (2). Trump said that he wanted to focus on healthcare and has proposed to:

- Repeal all of the Affordable Care Act;

- Allow the sale of health insurance across state lines;

- Make the purchase of health insurance fully tax deductible;

- Expand access to the health savings accounts;

- Increase price transparency;

- Block grant Medicaid;

- Lower entrance barriers to new producers of drugs.

In his 60 Minutes interview Trump reiterated that two provisions of the ACA prohibition of pre-existing conditions exclusion and ability for adult children to stay on parents insurance plans until age 26 - have his support (2). Other aspects of the ACA that might receive his support were not discussed.

On the Department of Veterans' Affairs Trump proposed to make the VA great again by removing corrupt and incompetent individuals who let our veterans down (1). The website goes on to say that only honest and dedicated public servants in the VA have their jobs protected, and will be put in line for promotions.

Several aspects of healthcare were not addressed. Universal healthcare which Trump has supported in the past was not discussed (3). Trump did not make major policy proposals for Medicare during the campaign and Medicare was not addressed on his website or during his interview.

According to a survey conducted by the Kaiser Family Foundation the top three healthcare issues concerning voters were:

- Ensuring that high-cost drugs for chronic conditions such as hepatitis and cancer become affordable;

- Lowering prescription drug costs in general;

- Making sure health plans have enough physicians and hospitals in their networks (4).

None were addressed on Trump's website or during his interview.

Richard A. Robbins, MD

Editor, SWJPCC

\section{References}

1. https://www.greatagain.gov/policy/healthcare.html (accessed 11/14/16). 
2. CBS News. President-elect Trump speaks to a divided country on 60 Minutes. November 13, 2016. Available at: http://www.cbsnews.com/news/60-minutesdonald-trump-family-melania-ivanka-lesley-stahl/ (accessed 11/14/16).

3. CBS News. Trump gets down to business on 60 Minutes. September 27, 2015. Available at: http://www.cbsnews.com/news/donald-trump-60-minutesscott-pelley/

4. Kirzinger A, Sugarman E, Brodie M. Kaiser Health Tracking Poll: October 2016. Available at: http://kff.org/health-costs/poll-finding/kaiser-healthtracking-poll-october-2016/ (accessed 11/14/16). 